\title{
Kinetic Model for pH Variation Resulted from Interaction of Aqueous Solution Contaminated with Nickel Ions and Cement Kiln Dust
}

\author{
Dooraid N. Ahmed $\left(D,{ }^{1}\right.$ Ayad A. H. Faisal, ${ }^{2}$ Salim H. Jassam, ${ }^{3}$ Laith A. Naji $\left(\mathbb{D},{ }^{3}\right.$ \\ and Mu. Naushad $\left(D^{4}\right.$ \\ ${ }^{1}$ Department of Mathematics, College of Education for Pure Sciences, University of Kirkuk, Kirkuk, Iraq \\ ${ }^{2}$ Department of Environmental Engineering, College of Engineering, University of Baghdad, Baghdad, Iraq \\ ${ }^{3}$ Technical Instructors Training Institute, Middle Technical University, Baghdad, Iraq \\ ${ }^{4}$ Department of Chemistry, College of Science, King Saud University, Riyadh, Saudi Arabia
}

Correspondence should be addressed to Laith A. Naji; add.ali.lith@gmail.com and Mu. Naushad; naushadksu@rediffmail.com

Received 1 December 2019; Revised 31 March 2020; Accepted 7 April 2020; Published 29 April 2020

Academic Editor: Franck Rabilloud

Copyright $\odot 2020$ Dooraid N. Ahmed et al. This is an open access article distributed under the Creative Commons Attribution License, which permits unrestricted use, distribution, and reproduction in any medium, provided the original work is properly cited.

Reaction term in the transport equation which described the migration of metal ions in the porous medium is frequently represented by conventional kinetic models such as pseudo-first order, pseudo-second order, and others. Unfortunately, these models are applicable for the constant value of solution $\mathrm{pH}$, and they cannot simulate the real situation in the field scale where this $\mathrm{pH}$ may be changed with time. Accordingly, the present study is a good attempt to derive the kinetic model that can simulate the change in the $\mathrm{pH}$ of the solution through solute transport. This was achieved by modifying the adsorption capacity and reaction constant to be functions in terms of solution $\mathrm{pH}$ by using semianalytical analysis and numerical approximation. The results proved that the kinetic model based on the numerical approximation (using exponential functions for adsorption capacity and reaction constant) symbolled as model 2 was more representative from other models applied for the description of interaction of nickel ions (with initial concentration of $400 \mathrm{mg} / \mathrm{L}$ ) and cement kiln dust with sum of squared error $\leq 1.54913$ and determination coefficient $\geq 0.889$. Also, the developed models had high ability for recognizing between pure precipitation and pure adsorption.

\section{Introduction}

Contamination of groundwater and surface water resources due to leakage of heavy metals such as cadmium, lead, mercury, chromium, nickel, zinc, and others from natural and anthropogenic activities are considered serious environmental problem [1-5]. Unlike the organic compounds, the heavy metals cannot be degraded, and the contaminated streams can be treated by separating these metals using conventional methods such as ion exchange [6,7], precipitation, air flotation, and adsorption [8-12]. Natural pollution with nickel is occurred due to pumped of groundwater from chalk aquifer where nickel is present within the pyrite nodules as in the southwestern Sweden and Denmark $[13,14]$.
The production of cement material is accompanied with the generation of large quantities of byproduct named cement kiln dust (CKD). It is a heterogeneous fine-grained solid of highly alkaline constituent due to the presence of a greatest percentage of limestone $[15,16]$. Discarding this byproduct to the ecosystem can associate with many problems that have negative impacts on the living and nonliving elements of the environment. So, reuse of CKD as reactive material in the remediation of wastewater streams is very valuable in the application of sustainability concepts, especially many agencies classified this material as nonhazardous solid waste $[17,18]$.

The major mechanisms responsible of the contaminant transfer during the treatment process due to the interaction of cement kiln dust (CKD) and aqueous solution 
contaminated with heavy metals have been proved in the previous studies. These studies clarified that the mechanisms include adsorption/desorption and precipitation/dissolution; unfortunately, the distinguishing between the mentioned mechanisms is not declared in the evidence approach. Many studies illustrated that the removal of heavy metals onto CKD is governed by pure adsorption within the specific range of initial $\mathrm{pH}$, and this can be attributed to the fine texture of this sorbent and presence of the metal oxide in its composition $[19,20]$. Actually, the $\mathrm{pH}$ of the contaminated water can be increased dramatically with the presence of CKD due to the high lime content and, consequently, metal hydroxide can be formed [21-23]. So, there is another mechanism rather than the pure adsorption which governed the treatment process which known as "pure precipitation." In addition, the last group of these studies is considered the treatment process as just interaction between contaminant and reactive material regardless which mechanism governed the removal of contaminant or what the contribution and adsorption when occurred together [24-26].

The interaction of CKD and water can cause a potential increase in the $\mathrm{pH}$ of aqueous solution as a function of the contact time, and this may be attributed to the gradual dissolution of calcium oxide. Kinetic models are mostly utilized to describe the kinetic data at certain value of $\mathrm{pH}$. Thus, when the $\mathrm{pH}$ varied with time (as for interaction of CKD and water), the kinetic model can be modified to take this situation into account by deriving the relationships related between kinetic constants and $\mathrm{pH}$ of the solution. Accordingly, the derivation and development of kinetic model as a function of solution $\mathrm{pH}$ will be more attractive for characterization between adsorption and precipitation when occurred together in the treatment process, and this is the significant point of this study. In the future, the present model can be incorporated with solute transport equation to reflect the effect of $\mathrm{pH}$ variation (which is the common state in the field scale) on the extent of the contaminant plume. Experimental outputs resulted from interaction of CKD and aqueous solution contaminated with nickel ions are used to verify the derived model.

\section{Derivation of Kinetic Model for CKD-Metal Ions Interaction}

Stepwise approach must be applied to represent the adsorption and precipitation mechanisms that resulted from interaction of aqueous solution of heavy metal and CKD as described previously. This approach is required to formulate each mechanism alone, and then the final results are collected together as follows [24, 27-29]:

(1) Metal (M) removal by precipitation:

$$
\begin{gathered}
\mathrm{X}_{2} \mathrm{O}+\mathrm{H}_{2} \mathrm{O} \longrightarrow 2 \mathrm{X}(\mathrm{OH}), \\
\mathrm{MSO}_{4}+2 \mathrm{X}(\mathrm{OH}) \longrightarrow \mathrm{M}(\mathrm{OH})_{2} \downarrow+\mathrm{X}_{2} \mathrm{SO}_{4},
\end{gathered}
$$

where $\mathrm{M}: \mathrm{Ni}$; X: K, Na.

The quantity of metal ions that captured by CKD particles $\left(q_{p}\right)$ due to pure precipitation may be determined by dividing the difference between initial concentration $\left(C_{o}\right)$ and remaining concentration $\left(C_{p}\right)$ after precipitation onto the CKD dosage $(m)$ for volume of sample $(V)$ as follows [30, 31]:

$$
q_{p}=\frac{V\left(C_{o}-C_{p}\right)}{m} .
$$

(2) Metal sorbed onto CKD particles:

$$
\mathrm{M}(\mathrm{OH})_{n}+\mathrm{CKD} \longrightarrow \mathrm{CKD}-\left\{\mathrm{M}(\mathrm{OH})_{n}\right\}
$$

The quantity of metal ions that captured by CKD particles $\left(q_{s r}\right)$ due to pure adsorption may be determined by dividing the difference between initial concentration and remaining concentration $\left(C_{s r}\right)$ after pure adsorption onto the CKD dosage $(m)$ as follows $[31,32]$ :

$$
q_{s r}=\frac{V\left(C_{o}-C_{s r}\right)}{m}
$$

Adsorption in combination with precipitation can cause total removal quantity of metal ions $(q)$ calculated based on the remaining concentration of these ions at time $(t)$ as follows [26]:

$$
q=\frac{\mathrm{V}\left(C_{o}-C_{t}\right)}{m} .
$$

Consequently,

$$
\begin{aligned}
q & =q_{s r}+q_{p}, \\
\frac{V\left(C_{o}-C_{t}\right)}{m} & =\frac{V\left(C_{o}-C_{s r}\right)}{m}+\frac{V\left(C_{o}-C_{p}\right)}{m}, \\
\left(C_{o}-C_{s r}\right) & =\left(C_{o}-C_{p}\right)-\left(C_{o}-C_{t}\right), \\
C_{s r} & =C_{o}-C_{t}+C_{p} .
\end{aligned}
$$

By substituting equation (10) into equation (5), the result will be

$$
q_{s r}=\frac{V\left(C_{t}-C_{p}\right)}{m} .
$$

(3) Kinetic models: these are very important in the prediction of the transfer rate of the metal ions from the liquid phase to the solid phase in the remediation process [33]. Previous studies are mainly based on the pseudo-first and pseudo-second order kinetic models in the description of this transfer rate [34]; however, more general expression named pseudo- $\mathrm{n}^{\text {th }}$ order kinetic model was derived to simulate the kinetic adsorption measurements as listed in Table 1. For kinetic precipitation measurements, theory on the kinetics of solid state chemical reaction was developed by Melvin Avrami (between 1939 and 1941) in the Columbia University, and the derived 
TABLE 1: Kinetic models used to describe the mechanisms governed the interaction of nickel ions and cement kiln dust.

\begin{tabular}{lcc}
\hline Mechanism & Model & Expression \\
\hline Sorption & Pseudo-first order & $q_{t}=q_{e}\left(1-e^{-k_{1} t}\right)$ \\
Precipitation & $n^{\text {th }}$ order & $q_{t 1}=q_{c 1}-\left(\left(n_{1}-1\right) k_{n} t^{a}+q_{c 1}^{1-n_{1}}\right)^{\left(1 / 1-n_{1}\right)}$ \\
\hline
\end{tabular}

$q_{t}$ and $q_{e}$ are the quantities of solute removed from the aqueous solution at time $t$ and at equilibrium, respectively, in (mg/g), $k_{1}$ is the pseudo-first order reaction constant $(1 / \mathrm{min})$, and $k_{n}$ is the pseudo- $n^{\text {th }}$ order reaction constant $(\mathrm{g} / \mathrm{mg} \mathrm{min})$.

equation (Table 1) can be utilized to describe the results of precipitation process [35-37].

(4) Modification of sorption kinetics model: derivation of the simultaneous sorption kinetic model for simulated $\mathrm{pH}$ effect must be introduced. Modification of reaction constant and adsorption capacity based on the effects of $\mathrm{pH}$ can be achieved either by semianalytical model or numerical model as follows:

(1) Semianalytical model: the nickel sorption phenomena are based on the following equation:

$$
a \mathrm{Ni}+b \mathrm{CKD} \longrightarrow c \mathrm{CKD}-\mathrm{Ni}
$$

So, the reaction constant of sorption process will be

$$
k_{1}=\frac{[\mathrm{CKD}-\mathrm{Ni}]^{c}}{[\mathrm{CKD}]^{b}[\mathrm{Ni}]^{a}}
$$

On the contrary, the sorption of the nickel hydroxide can be described by the following equations:

$$
\begin{gathered}
\gamma \mathrm{Ni}(\mathrm{OH})_{2}+\beta \mathrm{CKD} \longrightarrow \alpha \mathrm{CKD}-\mathrm{Ni}(\mathrm{OH})_{2}, \\
k_{2}=\frac{\left[\mathrm{CKD}-\mathrm{Ni}(\mathrm{OH})_{2}\right]^{\alpha}}{[\mathrm{CKD}]^{\beta}\left[\mathrm{Ni}(\mathrm{OH})_{2}\right]^{\gamma}} .
\end{gathered}
$$

The nickel hydroxide transformation is governed by the following equation:

$$
\gamma \mathrm{Ni}^{+2}+2 \gamma(\mathrm{OH}) \longrightarrow \gamma \mathrm{Ni}(\mathrm{OH})_{2}
$$

To find the relationship between the reaction constant and $\mathrm{pH}$, the summation of equations (14) and (16) may result in

$$
\begin{gathered}
\gamma \mathrm{Ni}^{+2}+2 \gamma(\mathrm{OH})+\beta \mathrm{CKD} \longrightarrow \alpha \mathrm{CKD}-\mathrm{Ni}(\mathrm{OH})_{2}, \\
k_{3}=\frac{\left[\mathrm{CKD}-\mathrm{Ni}(\mathrm{OH})_{2}\right]^{\alpha}}{[\mathrm{CKD}]^{\beta}[\mathrm{Ni}]^{\gamma}[\mathrm{OH}]^{\gamma}}=k_{3}=\frac{\mathrm{K}}{[\mathrm{OH}]^{\gamma}}=\mathrm{K}[\mathrm{OH}]^{-\gamma} .
\end{gathered}
$$

For more simplification,

$$
\begin{aligned}
k_{3} & =\mathrm{K} * 10^{-\gamma(\mathrm{pH}-14)} \\
\text { or } k_{3} & =\mathrm{K} * 10^{-(\mathrm{ApH}-\mathrm{B})} .
\end{aligned}
$$

Due to the change of $\mathrm{pH}$ with time, numerical relationship between $\mathrm{pH}$ and time can be suggested as follows:

$$
p H=\log _{10}\left(a t^{b}\right)
$$

So,

$$
\begin{aligned}
k_{3} & =\mathrm{K} * 10^{-B} *\left(a^{-A} t^{-b A}\right) \\
\text { or } k_{3} & =\mathrm{K} * a^{-A} * 10^{-B} * t^{-b A} .
\end{aligned}
$$

Let $\xi=K * a^{-A} * 10^{-B}$ and $\psi=-b A$, then

$$
k_{3}=\xi t^{\psi}
$$

By assuming that the one weakly acid functional group is responsible of sorption process, the sorption capacity $\left(q_{c}\right)$ can be written as follows [32, 38, 39]:

$$
q_{c}=\frac{Q_{1}+\left(Q_{2} * 10^{\mathrm{pH}-\mathrm{Pka}}\right)}{1+10^{\mathrm{pH}-\mathrm{Pka}}},
$$

where $k_{a}$ is the apparent equilibrium constant and $Q_{2}$ and $Q_{1}$ are the adsorption capacities for deprotonated $\left(\mathrm{A}^{-}\right)$and protonated $(\mathrm{AH})$ forms of functional group, and the reaction of equilibrium may be explained as

$$
\begin{aligned}
\mathrm{AH} & \leftrightarrow \mathrm{A}^{-}+\mathrm{H}^{+}, \\
\mathrm{pH} & =\log _{10}\left(a t^{b}\right), \\
q_{c} & =\frac{Q_{1}+\left(Q_{2} * 10^{\log _{10}\left(a t^{b}\right)-\mathrm{Pka}}\right)}{1+10^{\log _{10}\left(a t^{b}\right)-\mathrm{Pka}} .}
\end{aligned}
$$

For more simplification,

$$
\begin{aligned}
q_{c} & =\frac{Q_{1}+\left(Q_{2} * 10^{-\mathrm{Pka}} * a * t^{b}\right)}{1+10^{-\mathrm{Pka}} * a * t^{b}}, \\
\text { or } q_{c} & =\frac{Q_{1}+\left(Q_{2} * a * 10^{-\mathrm{Pka}} * t^{b}\right)}{1+10^{-\mathrm{Pka}} * a * t^{b}} .
\end{aligned}
$$

Let $\phi=Q_{2} * a * 10^{-\mathrm{Pka}}$ and $\Theta=10^{-\mathrm{Pka}} * a$, then

$$
q_{c}=\frac{Q_{1}+\left(\phi t^{b}\right)}{1+\theta t^{b}} \text {. }
$$

(2) Numerical kinetic model: the sorption process is mainly based on the $\mathrm{pH}$ of aqueous solution; so, the heavy metal with very acidic solution can be reacted easily with the protonated site. Hence, the identification of the operating mechanism depends on the presence of affinity series in agreement with the constant of hydrolysis. The complexity of this 
phenomenon may be due to the presence of various mechanisms of sorption that operated at different $\mathrm{pH}$ [40]. However, further investigations must be achieved to explore the behaviour of affinity series and sorbent selectivity under the $\mathrm{pH}$ effect. In the affinity series of systems with single metal, this metal with the highest affinity may rarely be affected by the existence of other heavy metals in solution [40, 41]. Due to the complexity of the phenomenon under consideration and to express of the sorption performance, the numerical model was utilized to simulate the influence of $\mathrm{pH}$. The kinetic model derived previously can be completed by using different numerical simulation functions that are based on the exponential model for representing of $\left(q_{c}\right)$ and $\left(k_{1}\right)$ (Table 2).

\section{Materials and Methods}

3.1. Mediums and Contaminant. Factory of Al-Kufa cement, Al-Najaf, Iraq was the source for CKD utilized as reactive material in the batch tests. This material has high percentage of Calcium oxide (approximately 46\%), and the dissolution of this constituent may be the primary cause for changing the acidity of the solution. For this reason, the $\mathrm{CKD}$ is chosen in the present study to recognize between adsorption and precipitation because they related with variation of solution $\mathrm{pH}$.

The nickel nitrate hexahydrate $\left(\mathrm{Ni}\left(\mathrm{NO}_{3}\right)_{2} \cdot 6 \mathrm{H}_{2} \mathrm{O}\right)$ manufactured by SD Fine-Chem Limited, India was dissolved in one liter of distilled water to prepare the stock solution with the initial concentration of $1000 \mathrm{mg} / \mathrm{L}$. To obtain the required concentration, stock solution must be diluted, and the $\mathrm{pH}$ of solution can be modified by adding base or acid as required.

3.2. Batch Experiments. The batch experiments are as follows:

(1) Total sorption (adsorption and precipitation): kinetic experiments are carried out at room temperature with initial $\mathrm{pH}=3$ where $50 \mathrm{~mL}$ volumes of aqueous solution contaminated with specific concentration of nickel ions must be distributed on the set of $250 \mathrm{~mL}$ flasks and $0.5 \pm 0.01 \mathrm{~g}$ of CKD added to each flask. Orbital shaker was used to agitate all flasks at a speed of $200 \mathrm{rpm}$ for duration not exceeding $180 \mathrm{~min}$; however, the filter paper can be utilized to separate the soil particles from aqueous solution after the end of agitation process. Certain volume $(\approx 10 \mathrm{~mL})$ of clear solution resulted after filtration from each flask was adopted to measure the residual concentration of nickel ions in the solution using the Shimadzu AA-6300 flame atomic absorption spectrophotometer at a wavelength equal to $232.2 \mathrm{~nm}$. Mass balance equation can be applied to find the quantity of metal ions sorbed to the CKD material.

(2) Pure precipitation: the procedure adopted in the present study to find the quantity of metal ions that precipitated due to the raise of solution $\mathrm{pH}$ is similar to the "tea-bag" experiment published in the previous studies [42]. $50 \mathrm{~mL}$ of uncontaminated water with $\mathrm{pH}$ of 3 was distributed into the set of $250 \mathrm{~mL}$ flasks, and a specific quantity of CKD $(=0.5 \pm 0.01 \mathrm{~g} / 50 \mathrm{~mL})$ must be added to each flask, and all mixtures were continuously agitated using a shaker for a period equal to $200 \mathrm{rpm}$ at room temperature. Thereafter, the solutions were filtered using the Whatman 6900-2504 PVDF GD/ X 25 Sterile Syringe Filter $(25 \mathrm{~mm}, 0.45 \mu \mathrm{m})$ to obtain the clear solution, and they have been mixed with the solution contaminated with nickel ions. The aim of this approach is to take the effect of CKD on the solution $\mathrm{pH}$ and, then, study the behavior of metal ions under the effect of this value of $\mathrm{pH}$ after separating the solid phase. However, the mixtures are agitated for equilibrium time, and then the precipitates are separated by filtration. The Shimadzu AA-6300 flame atomic absorption spectrophotometer can be used to measure the concentration of nickel ions still staying in these solutions; so, the precipitated concentration may be obtained by mass balance. The $\mathrm{pH}$ meter (type WTW pH 330i) was adopted to monitor the values of $\mathrm{pH}$ for solutions in all conducted tests.

\section{Results and Discussion}

Direct contact between the nickel ions and CKD sorbent during the experiments concerned the total sorption can increase the possibility of metal attachment on the particle surfaces. This is may be the main reason for the removal of metal ions without any delay, and conversely, remarkable lag can be observed in the removal of these ions by pure precipitation. For the interaction of nickel ions and CKD, pure adsorption must be determined as a complementary portion for precipitation share within the total sorption by using the developed previous equation (equation (10)) as plotted in Figure 1. Increasing the initial concentrations of metal ions according to this figure can cause a significant decrease in the total sorption, and this will associate with the increase of precipitation share while decreasing the adsorption share. The high reactivity of CKD in the change of solution $\mathrm{pH}$ will enhance the formation of nickel hydroxide, and it is considered the main cause for increasing the portion of precipitation process. Accordingly, reaching the adsorption capacity requires longer time because of the slow adsorption process in comparison with precipitation. Figure 2 and Table 3 show the trends and constants of the kinetic models which described the pure adsorption and 
TABLE 2: Selected approximations for constants of kinetic models for numerical approach.

\begin{tabular}{lccc}
\hline Model & Equation & $k$ & Type of model for \\
\hline Model 1 & $Q=q_{c 1}\left(1-e^{-a t^{b}+c}\right)$ & Exponential & Without modification \\
Model 2 & $Q=\left(q_{c} t^{\alpha}+\beta\right)\left(1-e^{-a t^{b}+c}\right)$ & Exponential & Exponential \\
Model 3 & $Q=q_{c} \exp (\mu t)\left(1-e^{-a t^{b}+c}\right)$ & Exponential & Exponential based on $(e)$ constant \\
Model 4 & $Q=q_{c 1}\left(1-e^{-z \exp (s t)}\right)$ & Exponential based on $(e)$ constant & Without modification \\
Model 5 & $\mathrm{Q}=\left(q_{c} t^{\alpha}+\beta\right)\left(1-e^{-z \exp (s t)}\right)$ & Exponential based on $(e)$ constant & Exponential \\
Model 6 & $\mathrm{Q}=\left(q_{c} \exp (\mu t)\right)\left(1-e^{-z \exp (s t)}\right)$ & Exponential based on $(e)$ constant & Exponential based on $(e)$ constant \\
\hline
\end{tabular}

$\mathrm{Q}$ is the quantity of solute removed from the aqueous solution at time $t(\mathrm{mg} / \mathrm{g}), q_{c 1}$ is the numerical constant $\left(\mathrm{mg} / \mathrm{g} \min ^{\alpha}\right)$, and $q_{c}$ is the quantity of solute removed from the aqueous solution at equilibrium $(\mathrm{mg} / \mathrm{g}) ; b, c, z$, and $\alpha$ are numerical constants $(-), \mu$ and $s$ are also numerical constants $(1 / \mathrm{min})$, and $a$ is the numerical constant $\left(1 / \mathrm{min}^{b}\right)$.

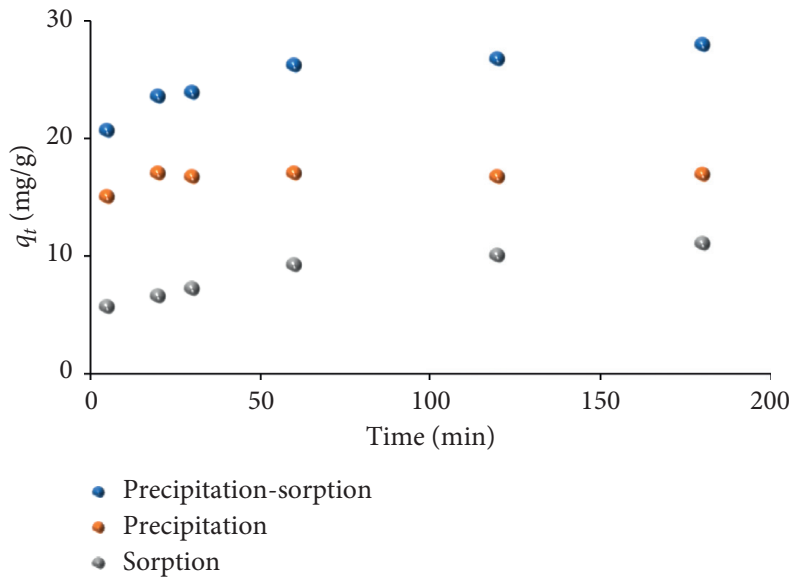

(a)

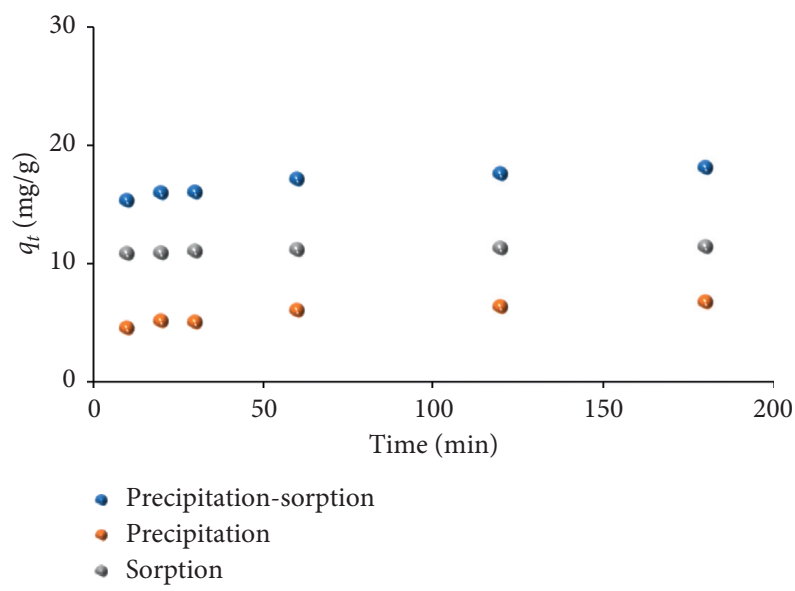

(c)

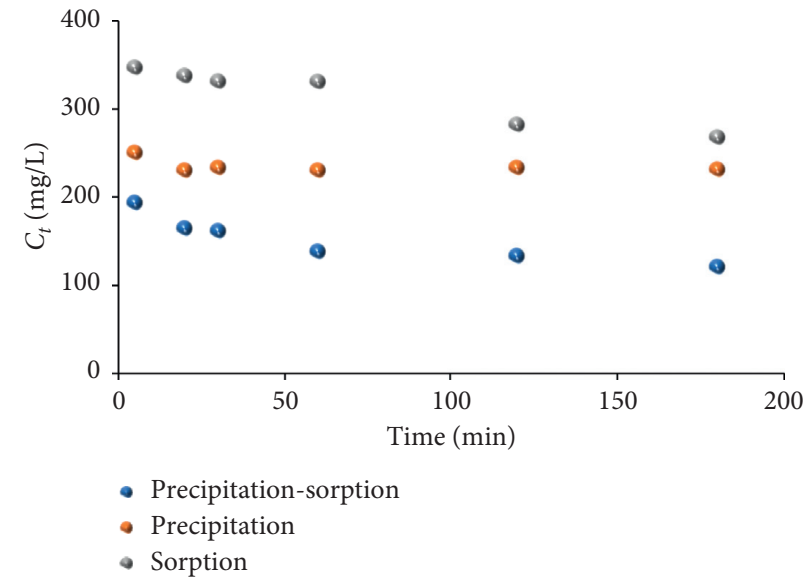

(b)

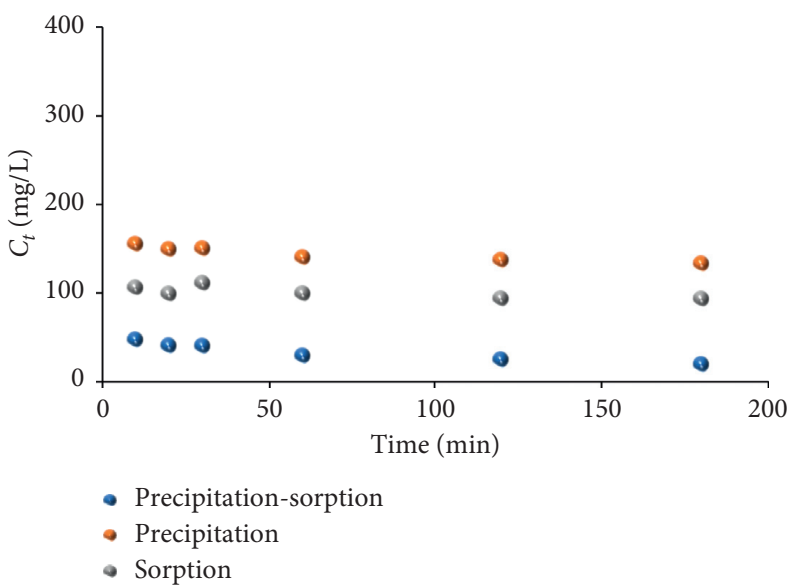

(d)

FIGURE 1: Variation of uptake capacities and remaining concentrations versus time for total sorption, sorption, and precipitation mechanisms at different values of initial nickel metal concentrations. (a) $C_{o}=400 \mathrm{mg} / \mathrm{L}$. (b) $C_{o}=400 \mathrm{mg} / \mathrm{L}$. (c) $C_{o}=200 \mathrm{mg} / \mathrm{L}$. (d) $C_{o}=200 \mathrm{mg} / \mathrm{L}$.

total sorption for interaction of nickel ions and CKD sorbent; however, poor matching can be recognized between the predicted and experimental results due to variation of $\mathrm{pH}$ versus the time.
In comparison with conventional models, the predictions of the modified kinetic models using semianalytical approximation presented a satisfactory agreement for the measured results of the pure adsorption as in Figure 3; 


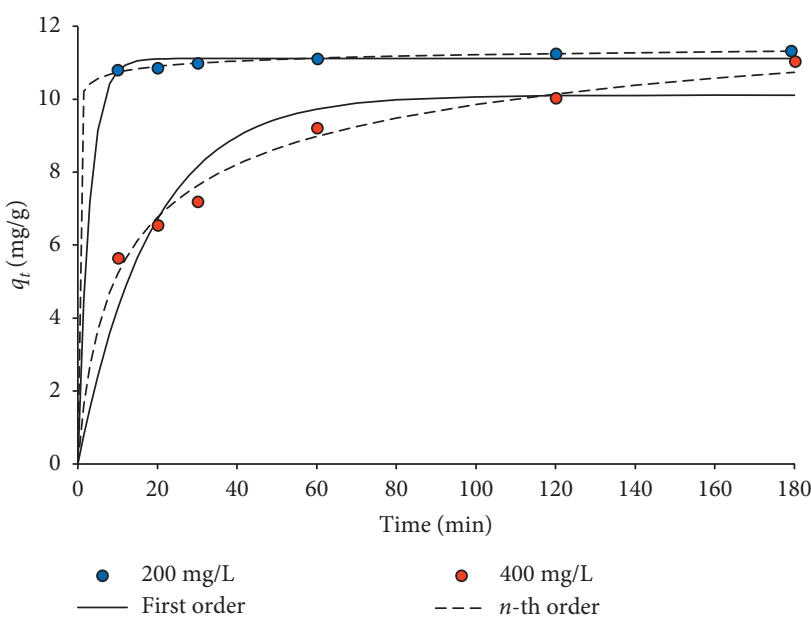

(a)

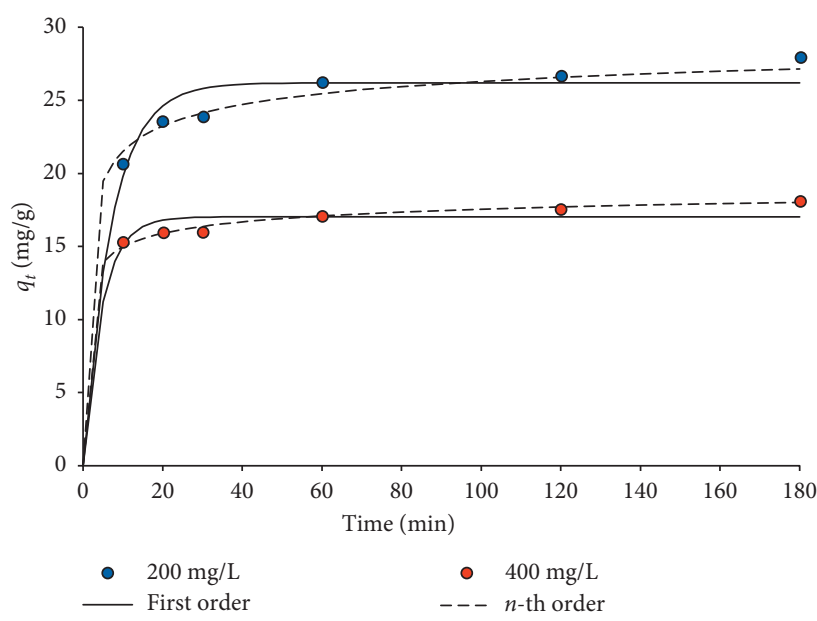

(b)

FIgURE 2: Kinetic model for nickel ions onto CKD particles as a result of total sorption and pure adsorption. (a) Sorption. (b) Adsorptionprecipitation.

TABLE 3: Simulation of predominant mechanisms by different kinetic models.

\begin{tabular}{|c|c|c|c|c|}
\hline \multirow{2}{*}{ Mechanism } & \multirow{2}{*}{ Name of model } & \multirow{2}{*}{ Parameter } & \multicolumn{2}{|c|}{$C_{o}(\mathrm{mg} / \mathrm{L})$} \\
\hline & & & 200 & 400 \\
\hline \multirow{9}{*}{ Precipitation-sorption } & \multirow{4}{*}{ First order } & $q_{c}$ & 17.03 & 26.19 \\
\hline & & $k_{1}$ & 0.215 & 0.141 \\
\hline & & $R^{2}$ & 0.460 & 0.620 \\
\hline & & SSE & 13.99 & 8.92 \\
\hline & \multirow{5}{*}{$n^{\text {th }}$ order } & $q_{c}$ & 21.280 & 32.436 \\
\hline & & $k_{n}$ & $6.931 * 10^{-6}$ & $1.883 * 10^{-6}$ \\
\hline & & $N$ & 5.397 & 4.967 \\
\hline & & $R^{2}$ & 0.961 & 0.854 \\
\hline & & SSE & 0.271 & 2.067 \\
\hline \multirow{9}{*}{ Sorption } & \multirow{4}{*}{ First order } & $q_{c}$ & 11.12 & 10.11 \\
\hline & & $k_{1}$ & 0.347 & 0.055 \\
\hline & & $R^{2}$ & 0.370 & 0.854 \\
\hline & & SSE & 0.160 & 4.040 \\
\hline & \multirow{5}{*}{$n^{\text {th }}$ order } & $q_{c}$ & 12.520 & 15.67 \\
\hline & & $\begin{array}{l}q c \\
k_{n}\end{array}$ & $202 * 10^{-6}$ & $6 * 10^{-6}$ \\
\hline & & $n$ & 8.320 & 4.489 \\
\hline & & $R^{2}$ & 0.973 & 0.974 \\
\hline & & SSE & 0.007 & 0.595 \\
\hline \multirow{5}{*}{ Precipitation } & \multirow{5}{*}{ Avrami } & $q_{c}$ & 16.860 & 11.377 \\
\hline & & $k_{1}$ & 0.166 & 0.319 \\
\hline & & $\mathrm{a}$ & 1.606 & 0.197 \\
\hline & & $R^{2}$ & 0.969 & 0.964 \\
\hline & & SSE & 0.092 & 0.132 \\
\hline
\end{tabular}

especially, the $n^{\text {th }}$ order model may be more representative than first order model. The constants (Table 4) of these models are calculated by the nonlinear regression analysis using "Solver" option within the Excel (2016).

For numerical kinetic models mentioned in Table 2, the nonlinear regression method with the first tentative values for the parameters of these models as determined by Excel were utilized to fit the experimental measurements at different periods of time. The fitted values for parameters of all numerical kinetic models are listed in Table 5; however, the scatter diagram for selected values of models under consideration is shown in Figure 4. Table 5 in combination with 


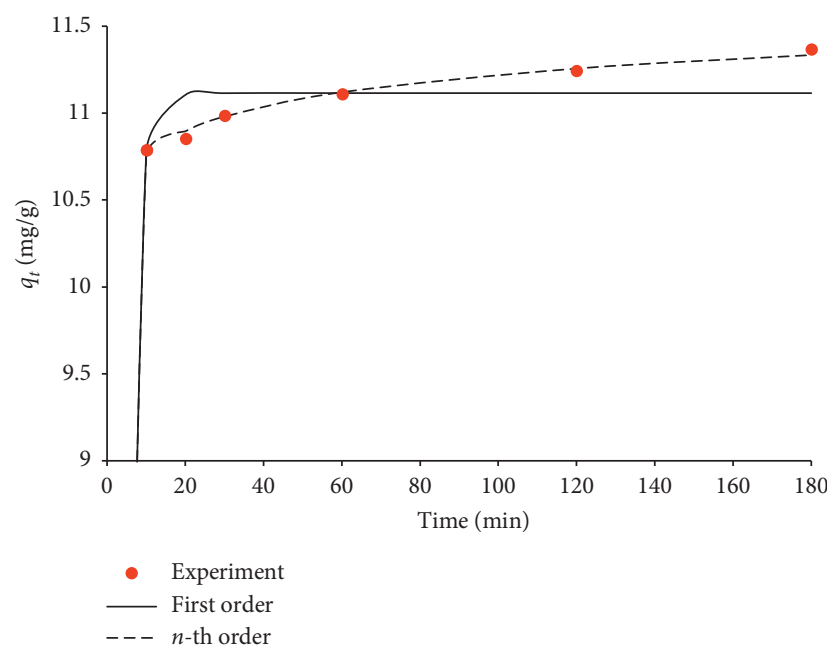

(a)

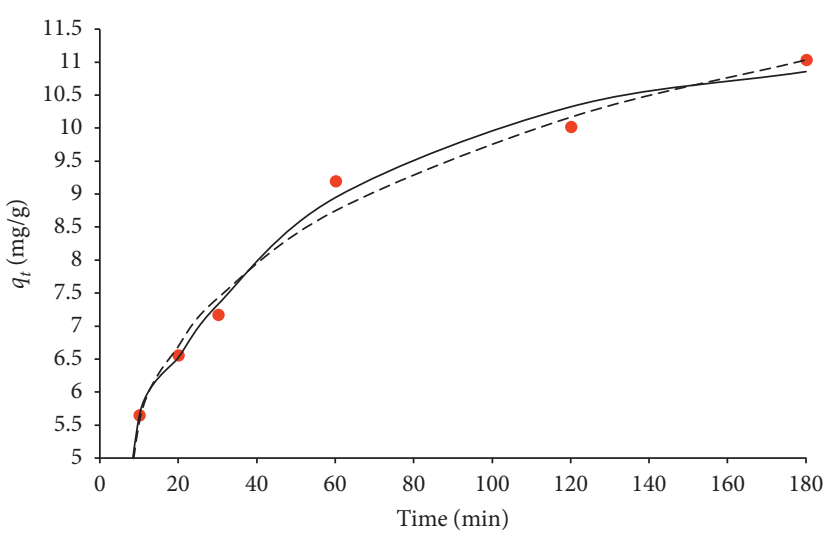

- Experiment

— First order - - $n$-th order

(b)

Figure 3: Semianalytical approximation for kinetic model to simulate the sorption kinetic data for initial concentration of (a) 200 and (b) $400 \mathrm{mg} / \mathrm{L}$.

TABLE 4: Parameters of different semianalytical models for sorption kinetic data of nickel ions-CKD interaction.

\begin{tabular}{lccc}
\hline \multirow{2}{*}{ Model } & Parameter & & $C_{o}(\mathrm{mg} / \mathrm{L})$ \\
& & 200 & 0.143 \\
& $\Gamma$ & 0.266 & 2.345 \\
& $\Psi$ & -0.137 & 52.093 \\
First order & $Q_{1}$ & 30.71 & 2.638 \\
& $\Theta$ & 1.800 & -0.089 \\
& $B$ & 0.052 & -20.470 \\
& $\Phi$ & 3.498 & 0.881 \\
& $R^{2}$ & 0.894 & 1.65 \\
\hline & SSE & 0.114 & 0.143 \\
$n^{\text {th }}$ order & $\Xi$ & $1.293 * 10^{-6}$ & 0.940 \\
& $\Psi$ & -1.202 & 1117.499 \\
& $Q_{1}$ & 23.546 & 109.981 \\
& $\Theta$ & 429.145 & -0.078 \\
& $B$ & -3.350 & -16.058 \\
& $\Phi$ & 4409.536 & 8.203 \\
& $N$ & 1.020 & 0.894 \\
& $R^{2}$ & 0.114 & 1.681 \\
\hline
\end{tabular}

TABle 5: Parameters of different numerical kinetic models for sorption kinetic data of nickel ions-CKD interaction.

\begin{tabular}{lccc}
\hline \multirow{2}{*}{ Model } & Parameter & 200 & $C_{o}(\mathrm{mg} / \mathrm{L})$ \\
& & 10.791 & 400 \\
\hline & $q_{c 1}$ & 0.080 & 17.74725 \\
Model 1 & $a$ & 1.440 & 4.477 \\
& $b$ & -0.189 & 0.054 \\
& $\mathrm{c}$ & 0.731 & 4.149 \\
& $R^{2}$ & 0.290 & 0.850 \\
& SSE & & 2.092 \\
\hline
\end{tabular}


TABle 5: Continued.

\begin{tabular}{|c|c|c|c|}
\hline \multirow{2}{*}{ Model } & \multirow{2}{*}{ Parameter } & \multicolumn{2}{|c|}{$C_{o}(\mathrm{mg} / \mathrm{L})$} \\
\hline & & 200 & 400 \\
\hline \multirow{8}{*}{ Model 2} & $q_{c}$ & 12.334 & 9.462 \\
\hline & $\alpha$ & -0.031 & 0.085 \\
\hline & $\beta$ & 0.001 & 0.001 \\
\hline & $a$ & 0.00001 & 0.00002 \\
\hline & $b$ & 3.860 & 4.416 \\
\hline & c & -1.826 & -1.751 \\
\hline & $R^{2}$ & 0.922 & 0.889 \\
\hline & SSE & 0.084 & 1.549 \\
\hline \multirow{7}{*}{ Model 3} & $q_{c}$ & 11.108 & 13.153 \\
\hline & $\mu$ & -0.00031 & 0.00155 \\
\hline & $a$ & 0.00001 & 0.00070 \\
\hline & $b$ & 3.938 & 0.796 \\
\hline & $c$ & -2.057 & -2.073 \\
\hline & $R^{2}$ & 0.864 & 0.733 \\
\hline & SSE & 0.147 & 3.716 \\
\hline \multirow{5}{*}{ Model 4} & $q_{c 1}$ & 10.787 & 14.892 \\
\hline & $z$ & 0.044 & 1.327 \\
\hline & $s$ & 0.400 & 0.008 \\
\hline & $R^{2}$ & 0.732 & 0.761 \\
\hline & SSE & 0.289 & 3.320 \\
\hline \multirow{7}{*}{ Model 5} & $q_{c}$ & 11.582 & 9.461 \\
\hline & $\alpha$ & 0.001 & 0.001 \\
\hline & $\beta$ & -0.017 & 0.085 \\
\hline & $z$ & 0.044 & 0.101 \\
\hline & $s$ & 0.389 & 0.311 \\
\hline & $R^{2}$ & 0.900 & 0.889 \\
\hline & SSE & 0.170 & 1.549 \\
\hline \multirow{6}{*}{ Model 6} & $q_{c}$ & 10.991 & 12.147 \\
\hline & $\mu$ & -0.0002 & -0.002 \\
\hline & $z$ & 0.044 & 0.099 \\
\hline & $s$ & 0.393 & 0.400 \\
\hline & $R^{2}$ & 0.833 & 0.742 \\
\hline & SSE & 0.180 & 73.713 \\
\hline
\end{tabular}

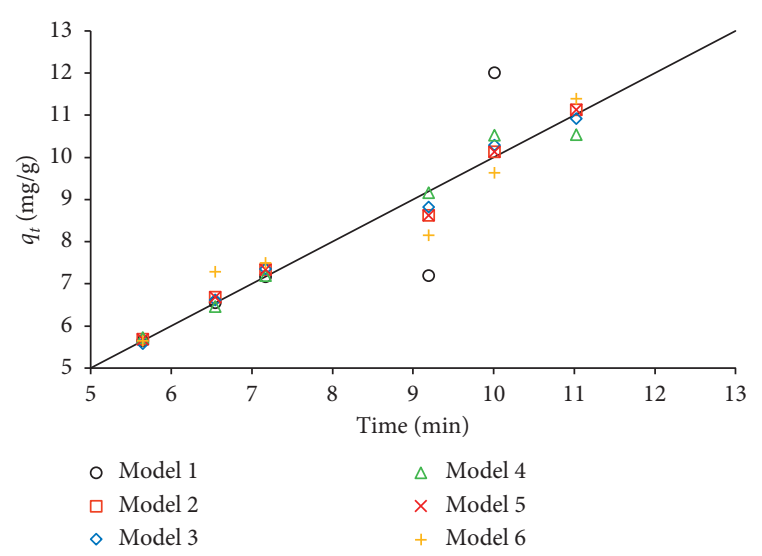

(a)

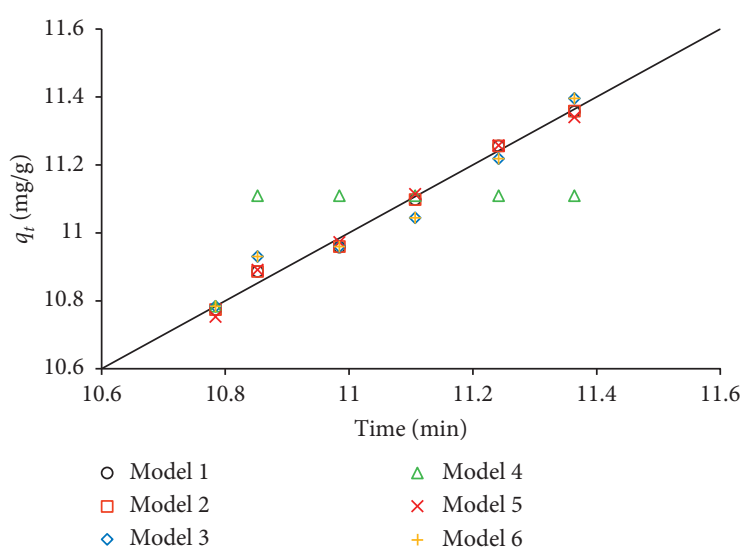

(b)

FIgUre 4: Continued. 


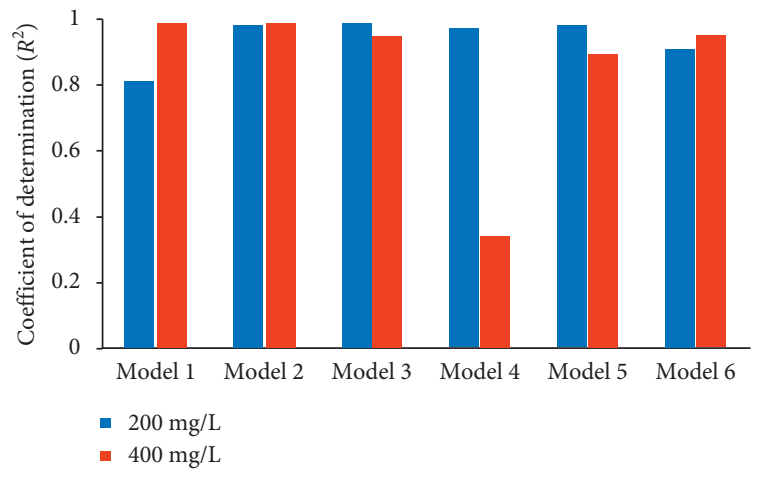

(c)

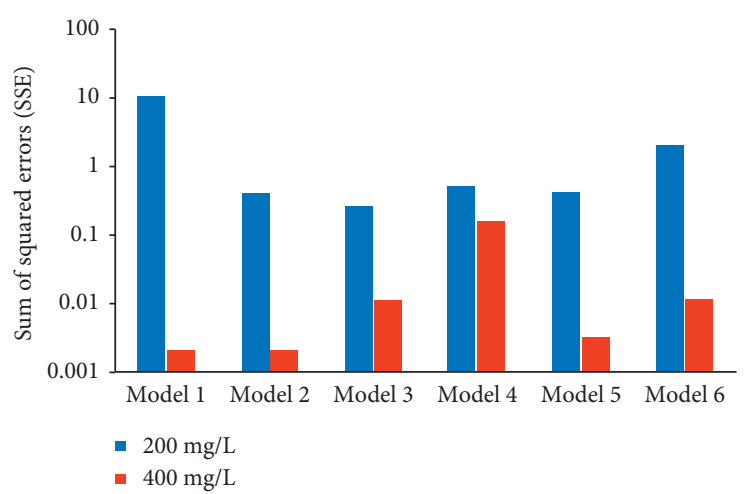

(d)

FIGURE 4: Scatter diagram with related statistical measures of numerical kinetic models for sorption kinetic data of nickel ions-CKD interaction. (a) $C_{o}=200 \mathrm{mg} / \mathrm{L}$. (b) $C_{o}=400 \mathrm{mg} / \mathrm{L}$. (c) $R^{2}$. (d) SSE.

Figure 4 signified that the model 2 is more dependent in the description of the kinetic experimental measurements for CKD-nickel ions interaction under the variation of the solution $\mathrm{pH}$ with sum of squared errors (SSE) $\leq .54913$ and coefficient of determination $\left(R^{2}\right) \geq 0.88862$.

\section{Conclusions}

The common situation in the real-field scale problems for propagation of metal ions in the subsurface medium is the variation of water $\mathrm{pH}$ versus the time and this definitely can influence the mechanism which governed the transport process. Accordingly, the finding of more suitable kinetic model that has high ability in the description of the transport process based on the set of kinetic measurements for interaction of nickel ions and CKD was developed. The present analysis was implemented to distinguish between the predominant mechanisms (i.e., total sorption, pure adsorption, and pure precipitation) by using traditional kinetic models. Then, modifications are achieved on the adsorption capacity $\left(q_{c}\right)$ and reaction constant $\left(k_{1}\right)$ of the kinetic model by applying semianalytical approximation as well as numerical models. Results proved that model 2 utilized the exponential approximation for $q_{c}$, and ( $k_{1}$ can lead to suitable representation for kinetic data under consideration with SSE $\leq 1.54913$ and $R^{2} \geq 0.88862$. This model is valuable and can be integrated with solute transport in the future to find the effect of variation of solution $\mathrm{pH}$ on the distribution of metal ions in the porous medium.

\section{Data Availability}

The data used to support the findings of this study are included within the article.

\section{Conflicts of Interest}

The authors declare that they have no conflicts of interest.

\section{Acknowledgments}

The authors would like to gratefully acknowledge the technical support of Environmental Engineering
Department, University of Baghdad, during this work. Mu. Naushad is grateful to the Researchers Supporting Project number (RSP-2019/8), King Saud University, Riyadh, Saudi Arabia, for the financial support.

\section{References}

[1] M. R. Awual, M. M. Hasan, M. Naushad, H. Shiwaku, and T. Yaita, "Preparation of new class composite adsorbent for enhanced palladium(II) detection and recovery," Sensors and Actuators B: Chemical, vol. 209, pp. 790-797, 2015.

[2] G. Sharma, D. Pathania, M. Naushad, and N. C. Kothiyal, "Fabrication, characterization and antimicrobial activity of polyaniline Th(IV) tungstomolybdophosphate nanocomposite material: efficient removal of toxic metal ions from water," Chemical Engineering Journal, vol. 251, pp. 413-421, 2014.

[3] M. R. Awual, G. E. Eldesoky, T. Yaita et al., "Schiff based ligand containing nano-composite adsorbent for optical copper (II) ions removal from aqueous solutions," Chemical Engineering Journal, vol. 279, pp. 639-647, 2015.

[4] A. Jamshaid, A. Hamid, N. Muhammad et al., "Cellulosebased materials for the removal of heavy metals from wastewater-an overview," ChemBioEng Reviews, vol. 4, no. 4, pp. 240-256, 2017.

[5] K. Khan, H. Khan, Y. Lu et al., "Evaluation of toxicological risk of foodstuffs contaminated with heavy metals in Swat, Pakistan," Ecotoxicology and Environmental Safety, vol. 108, pp. 224-232, 2014.

[6] M. Naushad and Z. A. ALOthman, "Separation of toxic $\mathrm{Pb}^{2+}$ metal from aqueous solution using strongly acidic cationexchange resin: analytical applications for the removal of metal ions from pharmaceutical formulation," Desalination and Water Treatment, vol. 53, no. 8, pp. 2158-2166, 2015.

[7] M. Naushad, A. Mittal, M. Rathore, and V. Gupta, "Ionexchange kinetic studies for $\mathrm{Cd}(\mathrm{II}), \mathrm{Co}(\mathrm{II}), \mathrm{Cu}(\mathrm{II})$, and $\mathrm{Pb}(\mathrm{II})$ metal ions over a composite cation exchanger," Desalination and Water Treatment, vol. 54, no. 10, pp. 2883-2890, 2015.

[8] A. A. H. Faisal, S. S. Alquzweeni, L. A. Naji, and M. Naushad, "Predominant mechanisms in the treatment of wastewater due to interaction of benzaldehyde and iron slag byproduct," International Journal of Environmental Research and Public Health, vol. 17, no. 1, p. 226, 2019.

[9] A. A. H. Faisal, Z. S. Nassir, L. A. Naji, M. Naushad, and T. Ahamad, "A sustainable approach to utilize olive pips for 
the sorption of lead ions: numerical modeling with aid of artificial neural network," Sustainable Chemistry and Pharmacy, vol. 15, Article ID 100220, 2020.

[10] Q. Chen, Z. Luo, C. Hills, G. Xue, and M. Tyrer, "Precipitation of heavy metals from wastewater using simulated flue gas: sequent additions of fly ash, lime and carbon dioxide," Water Research, vol. 43, no. 10, pp. 2605-2614, 2009.

[11] T. A. Kurniawan, G. Y. S. Chan, W.-H. Lo, and S. Babel, "Physico-chemical treatment techniques for wastewater laden with heavy metals," Chemical Engineering Journal, vol. 118, no. 1-2, pp. 83-98, 2006.

[12] A. Mittal, M. Naushad, G. Sharma, Z. A. Alothman, S. M. Wabaidur, and M. Alam, "Fabrication of MWCNTs/ $\mathrm{ThO}_{2}$ nanocomposite and its adsorption behavior for the removal of $\mathrm{Pb}(\mathrm{II})$ metal from aqueous medium," Desalination and Water Treatment, vol. 57, no. 46, pp. 21863-21869, 2016.

[13] F. Larsen and D. Postma, "Nickel mobilization in a groundwater well field: release by pyrite oxidation and desorption from manganese oxides," Environmental Science \& Technology, vol. 31, no. 9, pp. 2589-2595, 1997.

[14] L. A. Naji, A. A. H. Faisal, H. M. Rashid, M. Naushad, and T. Ahamad, "Environmental remediation of synthetic leachate produced from sanitary landfills using low-cost composite sorbent," Environmental Technology \& Innovation, vol. 18, Article ID 100680, 2020.

[15] EPA, Appendix A: Summaries of State Guidelines and Regulations on Reuse of Industrial By-Products, EPA, Washington, DC, USA, 2002.

[16] V. Oss, "Cement," Technical report, US Geological Survey, Washington, DC, USA, 2012.

[17] A. M. Mosa, A. H. Taher, and L. A. Al-Jaberi, "Improvement of poor subgrade soils using cement kiln dust," Case Studies in Construction Materials, vol. 7, pp. 138-143, 2017.

[18] Z. A. Baghdadi, M. N. Fatani, and N. A. Sabban, "Soil modification by cement kiln dust," Journal of Materials in Civil Engineering, vol. 7, no. 4, pp. 218-222, 1995.

[19] M. Al-Meshragi, H. G. Ibrahim, and M. M. Aboabboud, "Equilibrium and kinetics of chromium adsorption on cement kiln dust," in Proceedings of the World Congress on Engineering and Computer Science, San Francisco, CA, USA, October 2008.

[20] A. W. Taha, A. M. Dakroury, G. O. El-Sayed, and S. A. ElSalam, "Assessment removal of heavy metals ions from wastewater by cement kiln dust (CKD)," Journal of American Science, vol. 6, pp. 910-917, 2010.

[21] N. Zaki, I. Khattab, and N. Abdelmonem, "Removal of some heavy metals by CKD leachate," Journal of Hazardous Materials, vol. 147, no. 1-2, pp. 21-27, 2007.

[22] A. Mackie, M. E. Walsh, and C. B. Lake, Investigation Into the Use of Cement Kiln Dust (CKD) for Wastewater Treatment, Portland Cement Association: Research and Development Information, Skokie, IL, USA, 2010.

[23] A. L. Mackie and M. E. Walsh, "Bench-scale study of active mine water treatment using cement kiln dust (CKD) as a neutralization agent," Water Research, vol. 46, no. 2, pp. 327-334, 2012.

[24] M. Alshammari, M. F. Al Juboury, L. A. Naji et al., "Synthesis of a novel composite sorbent coated with siderite nanoparticles and its application for remediation of water contaminated with Congo red dye," International Journal of Environmental Research, vol. 14, no. 2, pp. 177-191, 2020.

[25] M. G. Klimantavièiûtë, D. Virbalytë, V. Pakðtas, R. Juðkënas, and A. Pigaga, "Interaction of heavy metal ions with cement kiln dust,” Ekologija, vol. 1, pp. 31-36, 2005.
[26] Z. T. Abd Ali, L. A. Naji, S. A. A. A. N. Almuktar et al., "Predominant mechanisms for the removal of nickel metal ion from aqueous solution using cement kiln dust," Journal of Water Process Engineering, vol. 33, Article ID 101033, 2020.

[27] A. A. H. Faisal, M. M. Ibreesam, N. Al-Ansari, L. A. Naji, M. Naushad, and T. Ahamad, "COMSOL multiphysics 3.5a package for simulating the cadmium transport in the sand bed-bentonite low permeable barrier," Journal of King Saud University-Science, vol. 32, no. 3, pp. 1944-1952, 2020.

[28] M. H. El-Awady and T. M. Sami, "Removal of heavy metals by cement kiln dust," Bulletin of Environmental Contamination and Toxicology, vol. 59, no. 4, pp. 603-610, 1997.

[29] C. Zhu, S. Martin, R. Ford, and N. Nuhfer, "Experimental and modeling studies of co-precipitation as an attenuation mechanism for radionuclides, metals, and metalloid mobility," Geophysical Research Abstracts, vol. 5, 2003.

[30] D. N. Ahmed, L. A. Naji, A. A. H. Faisal, N. Al-Ansari, and M. Naushad, "Waste foundry sand/MgFe-layered double hydroxides composite material for efficient removal of Congo red dye from aqueous solution," Scientific Reports, vol. 10, no. 1, p. 2042, 2020.

[31] L. Vinet and A. Zhedanov, "A "missing" family of classical orthogonal polynomials," Journal of Physics A: Mathematical and Theoretical, vol. 44, no. 8, pp. 085201-085226, 2011.

[32] L. A. Naji, S. H. Jassam, M. J. Yaseen, A. A. H. Faisal, and N. Al-Ansari, "Modification of Langmuir model for simulating initial $\mathrm{pH}$ and temperature effects on sorption process," Separation Science and Technology, pp. 1-8, 2019.

[33] P. R. Puranik, J. M. Modak, and K. M. Paknikar, "A comparative study of the mass transfer kinetics of metal biosorption by microbial biomass," Hydrometallurgy, vol. 52, no. 2, pp. 189-197, 1999.

[34] S. Lagergren, "About the theory of so-called adsorption of soluble substances," Kungliga Svenska Vetenskapsakademiens Handlingar, vol. 24, no. 4, pp. 1-39, 1989.

[35] A. A. H. Faisal, S. F. A. Al-Wakel, H. A. Assi, L. A. Naji, and M. Naushad, "Waterworks sludge-filter sand permeable reactive barrier for removal of toxic lead ions from contaminated groundwater," Journal of Water Process Engineering, vol. 33, Article ID 101112, 2020.

[36] K.-D. Li and K. Chen, "Kinetics modeling of precipitation with characteristic shape during post-implantation annealing," AIP Advances, vol. 5, no. 11, Article ID 117211, 2015.

[37] O. Bianchi, R. V. B. Oliveira, R. Fiorio, J. D. N. Martins, A. J. Zattera, and L. B. Canto, "Assessment of Avrami, Ozawa and Avrami-Ozawa equations for determination of EVA crosslinking kinetics from DSC measurements," Polymer Testing, vol. 27, no. 6, pp. 722-729, 2008.

[38] Q. Yu and P. Kaewsarn, "A model for $\mathrm{pH}$ dependent equilibrium of heavy metal biosorption," Korean Journal of Chemical Engineering, vol. 16, no. 6, pp. 753-757, 1999.

[39] N. Saad, Z. T. Abd Ali, L. A. Naji, A. A. A. H. Faisal, and N. AlAnsari, "Development of Bi-Langmuir model on the sorption of cadmium onto waste foundry sand: effects of initial $\mathrm{pH}$ and temperature," Environmental Engineering Research, vol. 25, no. 5, pp. 677-684, 2019.

[40] F. Pagnanelli, A. Esposito, L. Toro, and F. Vegliò, "Metal speciation and $\mathrm{pH}$ effect on $\mathrm{Pb}, \mathrm{Cu}, \mathrm{Zn}$ and $\mathrm{Cd}$ biosorption onto Sphaerotilus natans: Langmuir-type empirical model," Water Research, vol. 37, no. 3, pp. 627-633, 2003.

[41] M. Islam, N. Ahmed, M. Hossain, A. Rahman, and A. Sultana, "Effect of $\mathrm{pH}$ on the adsorption kinetics of $\mathrm{Cr}(\mathrm{VI})$ on sodium chlorite treated coconut coir," Bangladesh Journal of Scientific and Industrial Research, vol. 51, no. 2, pp. 95-100, 2016. 
[42] A. H. Sulaymon, A. A. H. Faisal, and Q. M. Khaliefa, "Simultaneous adsorption-precipitation characterization as mechanisms for metals removal from aqueous solutions by cement kiln dust (CKD)," Desalination and Water Treatment, vol. 57, no. 2, pp. 819-826, 2016. 